Portland State University

PDXScholar

\title{
Who Am I? Criminal Social Identity as a Mediator in the Relationship between Criminal Peers and Criminal Attitudes within a Sample of Probationers/ Parolees
}

Quinton Thomas Alexander

Portland State University

Follow this and additional works at: https://pdxscholar.library.pdx.edu/open_access_etds

Part of the Criminology Commons

Let us know how access to this document benefits you.

\section{Recommended Citation}

Alexander, Quinton Thomas, "Who Am I? Criminal Social Identity as a Mediator in the Relationship between Criminal Peers and Criminal Attitudes within a Sample of Probationers/Parolees" (2018). Dissertations and Theses. Paper 4479.

https://doi.org/10.15760/etd.6363

This Thesis is brought to you for free and open access. It has been accepted for inclusion in Dissertations and Theses by an authorized administrator of PDXScholar. Please contact us if we can make this document more accessible: pdxscholar@pdx.edu. 


\title{
Who Am I?
}

Criminal Social Identity as a Mediator in the Relationship between

Criminal Peers and Criminal Attitudes within a Sample of Probationers/Parolees

by

Quinton Thomas Alexander

A thesis submitted in partial fulfillment of the requirements for the degree of

\author{
Master of Science \\ in \\ Sociology
}

Thesis Committee:

Aaron Roussell, Chair

Melissa Thompson

Christopher Campbell

Portland State University

2018 


\begin{abstract}
Previous research has shown there to be a relationship between criminal peers and an individual's antisocial behavior and attitudes. Social literature lacks however empirical support for social identity theory, which suggests social identity serves as a mediator in the development of attitudes. Rather than a direct relationship where criminal peers influences the presence of criminal attitudes, this research suggests that criminal peers actually influences a mediator (i.e. an individual's social identity), which in turn influences their criminal attitudes. Thus, this mediation serves to clarify the nature of the seemingly apparent relationship between peers and attitudes. The current study, then, attempts to test the relationship between an individual's criminal associations and their criminal attitudes by introducing the individual's social identity as a mediator among individuals currently on probation or parole participating in a reentry program. This is done through the application of a survey constructed of three previously validated measures, and analyzed in two steps: firstly at the measurement level through confirmatory factor analysis; and secondly at the structural level through structural equation modeling.
\end{abstract}




\section{Dedication}

To Peggy Sue and Tom, the strongest people I know. I cannot give you enough credit for the role you have played in my life the past twenty-four years.

To my future self, who may one day realize the importance of these past two years, even if the outcome is not what we anticipated. 


\section{Acknowledgements}

This project would not have been possible without Dr. Aaron Roussell. You have proven to be an extraordinary mentor, advisor, and chair throughout this entire two-year process. Your input on my future life goals meant more than you may realize. Thank you.

To Dr. Melissa Thompson and Dr. Christopher Campbell who gave me wonderful constructive feedback on all iterations of this project. It has truly been a joy to work with you all.

To my cohort, who provided the encouragement and support necessary to make it through life as a graduate student. You all will stay with me in my travels and your presence will be missed.

To my best friend Doc. I cannot imagine this experience without you. Words just cannot describe what you mean to me and the positive impact you have had on my life and development. Here's to a lifetime of friendship. We finally did it man. 
Table of Contents

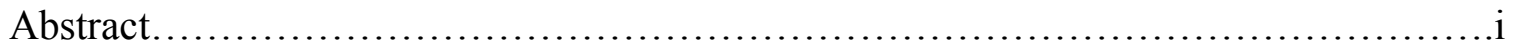

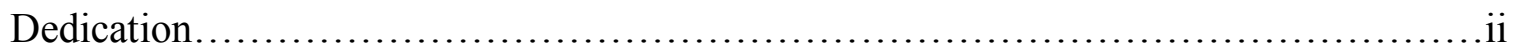

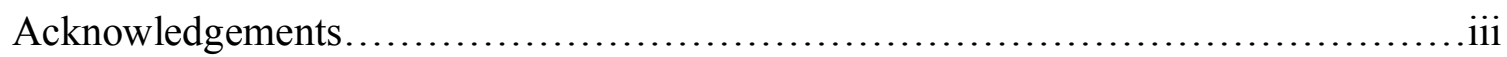

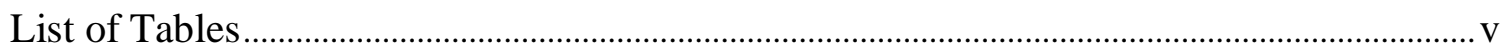

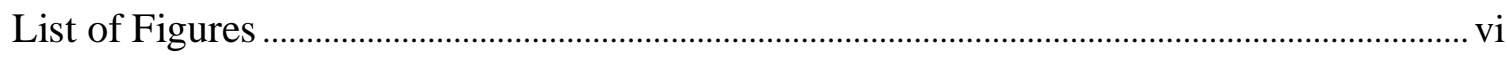

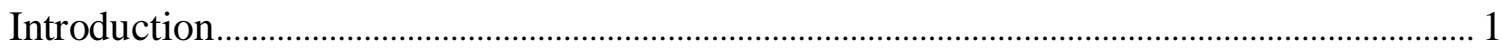

Literature Review/Theory .................................................................................................... 4

Theoretical Roots of Criminal Thinking ........................................................................ 4

Criminal Thinking and Relationships with Criminal Peers ..........................................

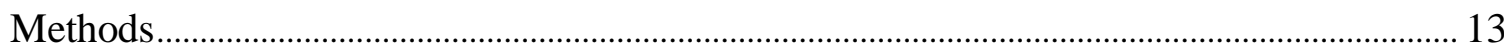

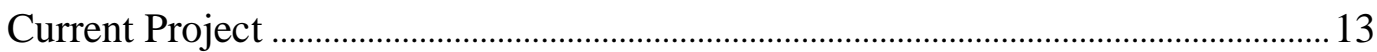

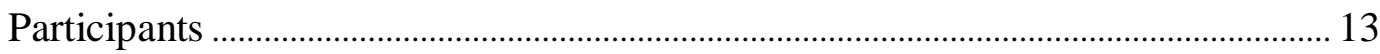

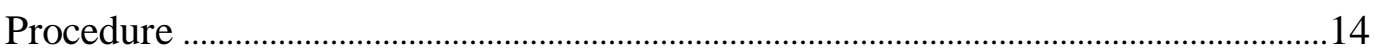

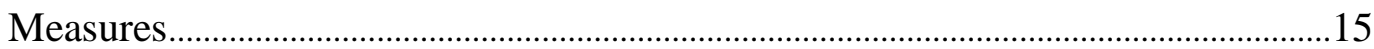

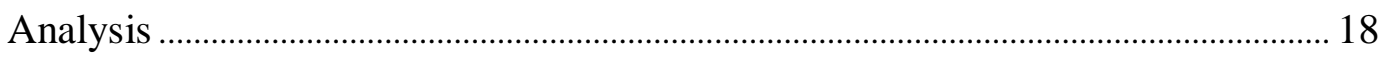

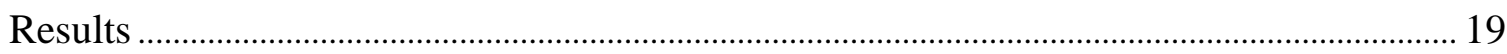

Descriptive Statistics and Correlations ........................................................................19

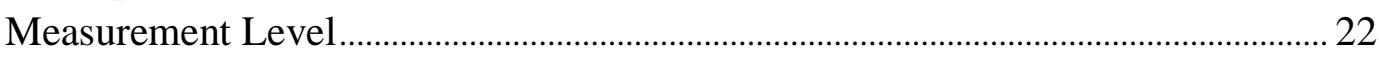

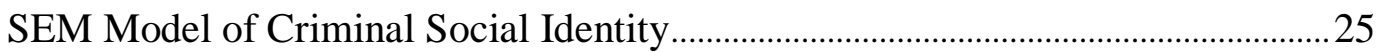

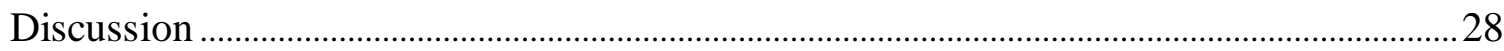

Significance of Study and Limitations .............................................................................. 30

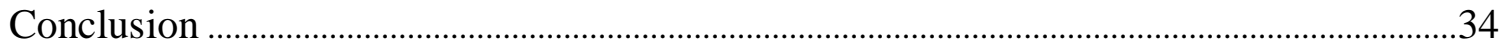

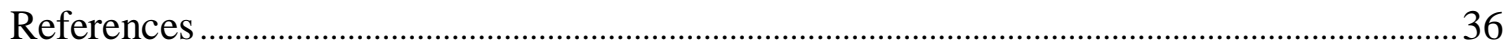

Appendices:

Appendix A: Recruitment Flyer ............................................................................ 40

Appendix B: Survey ……………………………………………………………... 41 


\section{List of Tables}

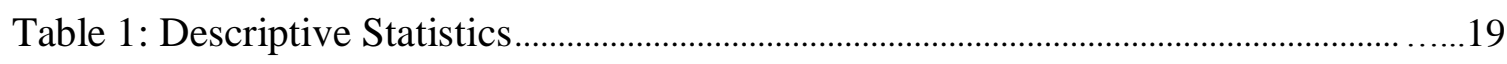

Table 2: Descriptive Statistics of the Measures Included in the Study .................................. 20

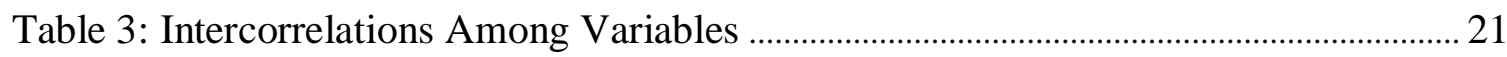

Table 4: Fit Indices for CFA Models of Criminal Social Identity …….................................23

Table 5: Correlations between CFRA Latent Factors ................................................................2

Table 6: Standardized and Unstandardized Factor Loadings for

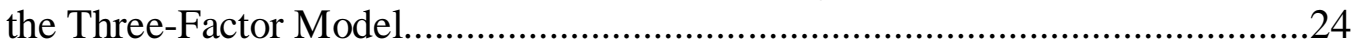

Table 7: Standardized and Unstandardized Regression Weights for the SEM of Criminal

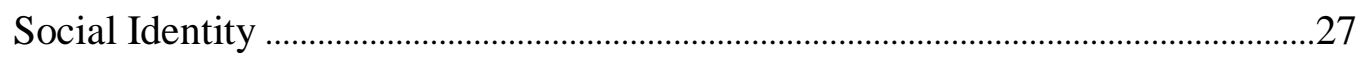




\section{List of Figures}

Figure 1: Conceptual SEM of Criminal Thinking Style ..............................................................25 


\section{Introduction}

Empirical studies of criminal behavior have indicated that an individual's thoughts or views on such behavior, referred to as criminal attitudes, are a significant predictor of an individual's involvement in criminal activity. This relationship has been extensively researched among social and criminal psychology research, suggesting that individuals who are oriented towards criminal behavior and those who have internalized a criminal concept - which involves the integration of attitudes, values, standards, and the opinions of other criminal peers into their identity - of said behavior are more likely to engage in criminal conduct (Andrews and Kandel, 1979; Bagozzi and Burnkrant, 1979; Simourd and VanDeVen, 1999; Vitaro, Brendgen, and Tremblay, 2000; Mills, Kroner, and Forth, 2002; Stevenson, Hall, and Innes, 2003; Engels, Luijpers, Landsheer, and Meeus, 2004; Nesdale, Maass, Kiesner, Durking, Griffiths, and James, 2009; Newberry and Birtchnell, 2011). Andrews and Bonta (1998) offered four general definitions of criminal behavior. An act is criminal if it: is prohibited by law and is punished by the state; is considered to violate a moral or religious code and is considered punishable by a supreme spiritual being; violates societal norms or traditions and is punishable by a community; or causes serious psychological stress or mental damage to the victim.

A meta-analytic review carried out by Gendreau, Little, and Goggin (1996) investigating different variables and their relationship to recidivistic behavior among adults revealed criminal peers and criminal attitudes to be the most significant predictors of recidivism. Previous research has also noted this relationship between criminal peers and criminal attitudes (Sutherland and Cressey, 1978; Sutherland, Cressey, and Luckenbill, 1992; Mills et. al., 2002; Mills, Anderson, and Kroner, 2004). This literature 
suggests there to be a direct, causal relationship between criminal peers and criminal attitudes and behaviors. This assumption however neglects to take into account the possible influence of the individual's social identity on the development of these attitudes and behaviors.

While the relationship between criminal peers and the development of criminal attitudes may initially seem apparent, social identity theory (SIT) suggests otherwise. Tajfel and Turner (1979) suggest that the acquisition of attitudes is actually mediated by an individual's identification with a specific social group. Mediation, in this instance, seeks to identify the role of an individual's social identity, which underlies the observed relationship between criminal peers and criminal attitudes. Rather than criminal peers directly influencing the presence of criminal attitudes, this project suggests that criminal peers actually induce a mediator (i.e. an individual's social identity), which in turn influences criminal attitudes. Thus, this mediation serves to clarify the nature of the seemingly apparent relationship between peers and attitudes. The introduction of SIT into the current literature is essential as it proposes that identity mediates the impact that social group members (i.e. criminal peers) play on an individual's development of thinking styles (i.e. criminal attitudes). For example, a high school student whose peers regularly cut class to smoke marijuana under the football field bleachers will likely form a social identity that aligns with those peers when they begin cutting class with their peers, which then in turn informs their attitudes towards particular delinquent behaviors.

It is through this suggested mediation that this study attempts to empirically test the mediating role of the criminal social identity in the process of the development of attitudes among probationers/parolees who are participating in a reentry program in 
Multnomah County. The questions of the current study then are: is the concept of a criminal social identity a valid measurement, and does this criminal social identity mediate the relationship between criminal peers and criminal attitudes? 


\section{Literature Review/Theory}

\section{Theoretical Roots of Criminal Thinking}

Walters (2006) defines criminal thinking as the thought content and cognitive processes conducive to the creation and maintenance of anti-social and criminal conduct. Sutherland's (1978) differential association theory has attempted to explain the development of criminal thinking, and it suggests that criminal attitudes are the result of an individual's association with other delinquent individuals who already possess these thinking styles and attitudes. It is these associations that are suggested to essentially serve as the base cause of delinquent behavior (Sutherland and Cressey, 1978; Sutherland, Cressey, and Luckenbill, 1992). In other words, differential association proposes that through interaction with others, an individual learns the attitudes, values, techniques, and motives of criminal behavior. Sutherland focuses particularly on how individuals learn to become criminals rather than why they become criminals, where how is the process through which the individual learns particular behaviors and why is the motivational factors or reasonings an individual may have for actually engaging in said behaviors. (Sutherland and Cressey, 1978). Differential association posits that an individual will engage in criminal activity when the balance of definitions for law-breaking exceeds those for law-abiding (Sutherland and Cressey, 1978). The earlier an individual comes under the influence of a particular group, the more likely that individual is to engage in the activities modeled to them (Sutherland and Cressey, 1978; Walters, 2006). This assertion does not ignore the fact that an individual may have more practical motives for committing a crime. That is to say, that if an individual is hungry but lacks the money to buy food, there is inherently a temptation to steal. 
It is important to note a critique of Sutherland's theory and how it pertains to this study. Much of said criticism focuses on an assumption that Sutherland was suggesting that interaction alone with criminals leads to criminal behavior. This notion that an individual being a criminal based on their environment alone is problematic, as it fails to take into account the individual's social identity or other internal factors that may affect their development of specific attitudes or their susceptibility to certain environmental influences (O'Grady, 2011). In addition to this, other criticisms point out the theory's inability to account for acts of deviance that are not learned or that are seemingly spontaneous (Scarpitti, Nielsen, and Miller, 2009). Take for example how an upperclass youth from a law-abiding family and who attends a private school commits a mass shooting; how can Sutherland explain this? This is another thing differential association does not concern itself with; however, as will be discussed below, Burgess and Akers' differential reinforcement theory (1966) expanded on Sutherland's theory and suggests that such criminal behavior could be due to non-social factors.

Sykes and Matza (1957) suggested that "a majority of criminals perceive themselves as conventional rather than as antisocial" and that "most of them try to rationalize and justify their criminal acts" (665). Neutralization theory was developed as a means to explain how offenders engage in criminal activity while negating their culpability or blame. Sykes and Matza posit that juveniles are not entrenched in delinquency, rather they "drift" between law-abiding and law-breaking behavior (1957). This is to say that juvenile delinquents are aware of the differences between law-abiding and law-breaking behavior and even understand law-breaking behavior to be wrong. Yet juvenile delinquents' actions and thoughts still drift between the two. Neutralization 
theory suggests that juveniles have some sense of an obligation to the law, and this obligation remains in place most of the time. However, when this obligation is strained, they tend to drift into crime. For example, when an employee's wages are cut they are able to more readily rationalize stealing from their employer because they are earning less money than before, essentially arguing that they deserve it. It is important to note here that, similarly to Sutherland's differential association theory, neutralization theory can be applied not only to juvenile populations, but also other criminal behaviors among a broad scope of individuals.

Neutralization theory was developed based on four observations made by Sykes and Matza of juvenile delinquent behavior .These observations are that juvenile delinquents: (1) express guilt over their illegal acts, (2) respect and even admire individuals who are honest and law-abiding, (3) differentiate between those they can victimize and those they cannot, (4) are not immune to the demands of conformity (1957). These four observations led Sykes and Matza to suggest five methods criminals use to rationalize and justify their criminal acts: denial of responsibility, denial of injury, denial of the victim, condemnation of the condemners, and appeals to higher authority (1957). Neutralization theory states that individuals are constantly aware of their "moral obligation to abide by the law" and that "they have the same moral obligation within themselves to avoid illegitimate acts" (Sykes and Matza, 1957:667). Sykes and Matza reasoned that when an individual did commit a criminal act or engaged in criminal behavior, they would have to employ the mechanisms discussed above to evade their moral obligations (1957). This being said, the methods posited by Sykes and Matza may 
not be significant factors in the initiation of criminal behavior; rather they are important in the maintenance of said behavior (Maruna and Copes, 2005).

In 1999, Mills and Kroner developed their take on criminal thinking styles based on four dimensions: attitudes towards violence, entitlement, antisocial intent, and attitudes towards criminal associates ${ }^{1}$ (Measure of Criminal Attitudes and Associates: Mills and Kroner, 1999). The associates sub-scale measures dispositions towards peers while the three sub-scales of violence, entitlement, and antisocial intent measure dispositions towards crimes. Their research suggests that the ability to predict violent criminal behavior is key to identifying individuals at high risk. Prior research also suggests that an individual's tolerance towards violence tends to be a strong predictor of their involvement in violent activities, more so than any other variable (Capara, Cinanni, and Mazzotti, 1989; Mills, Kroner, and Weekes, 1998). In addition, entitlement appears to be a good predictor for individuals engaging in criminal behavior.

\section{Criminal Thinking and Relationships with Criminal Peers}

Differential reinforcement theory, developed by Burgess and Akers, suggests that individuals are initiated into delinquency through differential association and antisocial peers (Akers, 1985). Then, through differential reinforcement, or the reinforcing only of appropriate or desired behavior(s), the individual gains the knowledge of how to reap rewards and avoid punishments as the actual or anticipated consequences of particular behaviors. This theory is often used in criminological literature due to the fact that it "provides an explanation of the decision-making process involved in the development of the cognitive (criminal attitudes), behavioral, and motivational techniques essential to

\footnotetext{
${ }^{1}$ The terms peers and associates are used interchangeably throughout the literature. The use of the term associate in this measure is equivalent to the term peers throughout the rest of the project.
} 
commit a criminal act" (Boduszek, Adamson, Shevlin, Hyland, and Bourke, 2013:16). This theory gets yet one step closer to completely filling the hole left by the theories discussed above in that it analyzes the actual thought process of engaging in criminal acts.

Holsinger (1999) suggests that individuals who are socialized in criminal settings and have attitudes towards criminal behavior are more likely to commit a crime in the future. According to Holsinger (1999), criminal behavior can be better understood by looking at criminal and non-criminal populations together. Essentially, individuals who have internalized pro-social attitudes from a pro-social environment are less likely to engage in criminal behavior as opposed to individuals who have been socialized in anti-social environments and internalized anti-social attitudes. His findings, similar to those discussed in earlier sections, suggest that individuals who hold more persistently favorable attitudes, feelings, and/or thoughts towards crime via their associations with criminal peers, tend to commit more crimes than individuals who possess pro-social attitudes (1999). Findings from a study by Backstrom and Bjorklund (2008) using a sample of Swedish non-criminal and criminal samples on the four sub-scales of the Measure of Criminal Attitudes and Associates (Mills and Kroner, 1999), which will be discussed further in the methods section, found significant mean differences between the two groups on each particular subscale (violence, entitlement, anti-social intent, and associates). Backstrom and Bjorklund (2008) posited that individuals within the criminal sample possessed significantly higher levels of criminal attitudes and anti-social peers when compared to the non-criminal sample. In further support of these findings, Losel (2003) also suggests that delinquent individuals develop attitudes, values, and cognitions 
through interactions with group influences that encourage criminal behavior. In addition, Andrews and Kandel (1979) and Mills et. al. (2002; 2004) posit that the influence of criminal peers interacts with an individual's criminal attitudes, and when these variables are strongly associated, "the relationship to criminality is especially strong” (Boduszek, Adamson, Shevlin, Hyland, and Bourke, 2013:16). Similarly, Rhodes (1979) reported that individuals who enter prison with a relatively low level of criminal attitudes will often acquire more deviant criminal attitudes during their sentence due to continual contact with other criminals and prison guards.

These findings suggest that association with criminal peers contributes to the perception of resemblance with in-group criminals. They also suggest that through one's interactions with peers who are involved in criminal activity, individuals develop a strong belief about the importance and value of belonging to a criminal group.

Social identity theory (SIT; Tajfel and Turner, 1979) suggests that particular groups to which individuals belong are an important source of both pride and selfesteem. That is to say, the groups we identity with tend to give us some sense of social identity or a sense of belonging to the social world. The best way to describe SIT is as a theory that predicts inter-group behaviors (particularly the discrimination against outgroup members) on the basis of an individual's perceived group status differences, perceived legitimacy and stability of those particular differences, and perceived ability to move from one group to another (Tajfel and Tuner, 1979).

Tajfel and Turner (1979) suggest that there are three processes by which an individual evaluates others as "us" or "them" (i.e., in-groups and out-groups respectively) which occur in a particular order. Social categorization, the first mental process, involves 
an individual categorizing both themselves and others in order to gain an understanding of their social environment. This categorization includes categories such as race (e.g., black, white), religious affiliation (e.g., Christian, Buddhist, etc.) and occupations (e.g., student, faculty) among many others that are necessary in order for day-to-day interaction to take place. This categorization tells us about the individuals with whom we are interacting, which allows us to successfully interact with them in the way the categories require. Not only does an individual discover things about the others with whom they are interacting, but social categorization allows them to discover things about themselves as well. The subject defines appropriate behavior by referencing said behavior against normative expectations of their group. This first step may seem analogous to the process itself, but there is a difference between evaluating others as "us" or "them" and categorizing individuals into particular groups. The categorization precedes the more indepth evaluation of the groups as separate. The next step is social identification, where an individual adopts the identity of the group into which they have categorized themselves and attaches meaningful emotions to that identity. Take for example an individual categorizing themselves as a student. Due to this categorization of themselves, the chances that they will adopt the identity of a student as well as act in alignment with how they believe students should act are quite high. An emotional significance to that identification with a group, as well as an individual's self-esteem will become bound and reliant upon that group membership. Lastly is social comparison. Once an individual has categorized themselves as a member of a group and have identified with that group, they tend to compare that group with other groups. If their self-esteem is to be maintained, they must compare their group favorably to others. Here, Tajfel and Turner (1979) 
suggest that "individuals' attitudes toward in-group members ultimately develop from their need to identify with and belong to groups that are perceived to be relatively superior" (35). The result of this then is the individual becomes disposed to perceiving ingroup members as being similar to themselves and thus exhibit preferences towards those in-group members (Boduszek, Adamson, Shevlin, Hyland, and Bourke, 2013). This depersonalization is what shifts personal identity to social. ${ }^{2}$ "This process not only depersonalizes self-perception but transforms self-conception and assimilates all aspects of one's attitudes, feelings, and behaviors to the in-group model; it gives rise to changes in what people think, feel, and do" (Hogg, 2001:190).

Depersonalization suggests that an individual's social identity serves as a mediator in the development of thinking styles that are expected and endorsed by a given social group. Research conducted by Hogg and Smith (2007) suggests that research focusing on attitudes and behavior should be approached from the psychology of groups and inter-group relations, "particularly from the theoretical perspective of social identity" (90). They posit that the most fundamental aspect in which social identity affects an individual's attitudes is self-categorization:

"Categorization of self, self-categorization, transforms self-conception to match the identity described by the category, and transforms one's perceptions, attitudes, feelings, and conduct to conform to the category prototype. Self-categorization configures and changes one's identity and one's attitudes. It depersonalizes our attitudes so that they conform to our in-group prototype, and this represents genuine attitude change, not superficial behavioral compliance" (Hogg and Smith, 2007:96).

Literature, particularly in the field of criminal psychology, has almost exclusively focused on investigating the direct causal relationship between criminal peer associations

\footnotetext{
${ }^{2}$ Depersonalization refers to viewing oneself as a representative category rather than a unique individual, and it results in a change of identity (Boduszek, Dhingra, and Debowska, 2016). Depersonalization should not be confused with deindividuation (Zimbardo, 1970) which is a loss of identity.
} 
and the development of criminal thinking styles (Boduszek, Adamson, Shevlin, Hyland, and Bourke, 2013). This being said, very little research has been done to investigate the predictions of SIT as a valid addition to the model as a means of understanding the development of criminal attitudes and behaviors. By introducing SIT, this research will be able to address the holes left by differential association and social learning theories by adding the role an individual's social identity plays in the learning and formation of behaviors and attitudes. This study attempts to show that an individual's criminal social identity acts as an essential mediating factor in the relationship between associations with criminal peers and criminal attitudes. 


\section{Methods}

\section{Current Project}

Previous research has shown there to be a relationship between criminal peers and an individual's antisocial behavior and attitudes. Social literature lacks however empirical support of SIT, which suggests social identity serves as a mediator in the development of attitudes. Rather than a direct relationship where criminal peers influences the presence of criminal attitudes, this project suggests that criminal peers actually influences a mediator - an individual's social identity -, which in turn influences their criminal attitudes. This mediation serves to clarify the nature of the seemingly apparent relationship between peers and attitudes. The current study attempts to test firstly the hypothesized efficacy of the Measure of Criminal Social Identity (MCSI) in measuring the concept of the criminal social identity among a population of probationers/parolees; and secondly the hypothesized mediating role of said criminal social identity in the relationship between an individual's criminal peers and their criminal attitudes. This is done through the application of a survey comprising three previously validated measures discussed in the next section.

H1: I expect to find that the criminal social identity can be validly measured among a population of probationers/parolees using the MCSI.

$\mathrm{H}_{2}$ : I expect that the criminal social identity will act as a mediator in the relationship between an individual's peers and criminal attitudes.

\section{Participants}

The convenience sample consisted of 200 individuals attending a reentry program who are currently on probation, parole, bench probation, post-prison supervision, or close 
street supervision in Multnomah County. General demographic information of the reentry programs were unavailable in order to compare the sample population. Of the 200 individuals, $99(49.5 \%)$ were female, 94 (47\%) were male, and 7 (3.5\%) were nonbinary/other. The respondents ranged in age from 19 to 50. The average age of the participants was $30.77(M=30.77$, standard deviation $[S D]=8.03)$. The sample consisted of $89(44.5 \%)$ burglars/thieves, 25 (12.5\%) drug offenders, 82 (41\%) violent offenders, and $4(2 \%)$ sex offenders. These offences were the individuals' most recent offences for which they were participating in the program, as prior offences were not recorded in the survey. Of the 200 participants, 109 (54.5\%) lived in urban areas, 86 $(42.5 \%)$ lived in suburban areas and $5(2.5 \%)$ resided in rural areas. In regards to education, $33(16.5 \%)$ respondents reported having a high school education or GED, 82 (41\%) had attained a secondary school/college education, and $6(3 \%)$ had attained a graduate level degree. 107 (53.5\%) participants reported their marital status as single, 53 (26.5\%) as living with partner, $29(14.5 \%)$ as married, 7 (3.5\%) as divorced/separated, and $4(2 \%)$ as widowed/widower.

\section{Procedure}

The sample was recruited over a 4 month period at several reentry programs in Multinomah county. Participants responded to a sixty-five item survey lasting between forty-five minutes to an hour. The survey is composed of three previously validated psychosocial assessments (Appendix B). The survey was verbally administered, which allowed compensation for any discrepancies in reading ability or education level, and enabled engaged clarification. Respondents were given a physical copy of the survey upon which they recorded their responses to the questions. 
The sample was recruited via flyers posted at the reception desks of the reentry centers which outlined what was being investigated, what participation in the study entailed, and how to get into contact with the researcher (Appendix A). Participants were also recruited by the program heads who put the individuals they believed qualified for the research in contact with the researcher. The possible impacts of this are discussed further in the Significance of Study and Limitations section. Surveys were administered to the participants by the researcher one-on-one in a private room on site at the reentry center.

To ensure anonymity, no identifiable information was associated with surveys (e.g. name, birth date, etc.). Each survey was randomly assigned a number. Hard copies of the surveys were kept in a locked file cabinet in a locked personal office, to which only the researcher had the key. Electronic copies of the survey data were kept on a password protected computer in a password protected file.

Measures

The Measure of Criminal Attitudes and Associates (Mills and Kroner, 1999) is a two-part retrospective self-report survey of criminal thinking styles and relationships with criminal peers. Part A of the survey attempts to quantify criminal associations and relations. Respondents are asked to recall four individuals "with whom they spent most of their time before incarceration" (1999:4) and then answer four questions regarding the "degree of criminal involvement of their associates": (1) "Has this person ever committed a crime?" (2) "Does this person have a criminal record?" (3) "Has this person ever been to jail?" and (4) “Has this person tried to involve you in a crime?". Two measures of criminal associations and relations are analyzed using the responses. "Number of 
Criminal Friends" is calculated using the sum of the number of friends the respondent answers "yes" to any questions on criminal association. "Criminal Friend Index" (CFI) is calculated by assigning 1 through 4 to the percent of free time spent with each individual (0\%-25\%; 25\%-50\%; 50\%-75\%; 75\%-100\%). That number (1 through 4$)$ is then multiplied by the number of "yes" responses to the four questions regarding criminal association. The potential scores for the CFI range from 0 to 64, with higher scores indicating a stronger association with criminal peers.

Part $B$ is a 46-item survey of criminal thinking style/attitudes that includes four sub-scales: violence (12 items), entitlement (12 items), antisocial intent (12 items), and associates (10 items). Sample items include: "It's understandable to hit someone who insults you" (violence); "A person is right to take what is owed them, even if they have to steal it" (entitlement); "For good reason, I would commit a crime" (antisocial intent); and "I have a lot in common with people who break the law" (association). Item responses are dichotomous "yes" or "no". Each approval on an antisocial item (or rejection on a prosocial item) receives 1 point, where each rejection of an antisocial item (or approval of a pro-social item) receives 0 points. Scores are summed for each sub-scale, where higher scores reflect higher criminal attitudes.

The Measure of Criminal Social Identity (MCSI: Boduszek, Adamson, Shevlin, and Hyland, 2012) is an eight-item survey to measure an individual's criminal social identity. Each item is scored on a 5-point Likert scale: 1=strongly disagree, $2=$ disagree, $3=$ sometimes, 4=agree, 5=strongly agree. Three items within the scale are scored in reverse direction (i.e. $1=$ strongly agree and 5=strongly disagree): (1) Being a criminal has little to do with how I feel about myself in general; (3) The fact I am a criminal rarely 
enters my mind; (8) I find it difficult to form a bond with other people who have committed a crime. Possible scores range between 8 and 40, with higher scores indicating higher levels of criminal social identity. The survey includes three sub-scales: Cognitive Centrality (3 items) measures the "psychological salience of an individual's group identity" (Boduszek, Adamson, Shevlin, Hyland, and Bourke, 2013:18); In-Group ties (3 items) measures the "level of bonding with other criminals" (Boduszek et. al., 2013:18); and In-Group Affect ( 2 items) measures an individual's "felt attitude toward other ingroup criminals" (Boduszek et. al., 2013:18). Sample items that measure each aspect of criminal social identity include: "I often think about being a criminal" (Cognitive Centrality ${ }^{3}$ ); "In general I am glad to be a part of criminal group" (In-Group Affect); and "I have a lot in common with other people who committed a crime" (In-Group Ties).

The Measure of Peer Rejection ${ }^{4}$ (Mikami, Boucher, and Hymphreys, 2005) is a seven-item retrospective survey with a 5-point Likert scale response ranging from a negative answer (1) to a positive (5) with one item reverse-scored. The total response score ranges between 7 and 35, with higher scores indicating more positive peer relations and an absence of peer rejection. Respondents are asked to indicate the amount of peers they liked opposed to disliked before incarceration (e.g. "How many students in your class did you get along with?"). Respondents are also asked the number of peers who they believe respected them as opposed to those who did non (i.e. "How many students in your class teased you, put you down, or picked on you?’).

\footnotetext{
${ }^{3}$ Kameda, Ohtsubo, and Takezawa (1997) suggest that just as people share social links within a group, they also share cognitive links. Cognitive connections among group members are measured in terms of how much information they hold in common, thus a cognitively central member is someone whose knowledge is predominately shared with other members (Abele, Vaughan-Parsons, and Strasser, 2008).

${ }^{4}$ Peer, in the context of this measure, refers specifically to members of an individual's high school class rather than the general use of peers/associates in the rest of this project. 
Analysis

Analysis of the data occurred in two steps, first at the measurement level and second at the structural level. At the measurement level, three alternative models of criminal social identity (Figure 1) were specified and estimated in SPSS Amos version 24 using confirmatory factor analysis (CFA), which helped to determine the factor structure and loadings of measured variables as well as assess the fit between the data and theoretical models. CFA was conducted specifically in order to determine the efficacy of the MCSI in its measurement of the concept of the criminal social identity among a population of probationers/parolees (Table 4). The MCSI was previously validated among a population of incarcerated adult male individuals in Pakistan, Poland, and Asia in medium- to high-security prisons.

At the structural level, the conceptual model of criminal thinking style (Figure 1) was specified and estimated in Onyx version 1.0-991 using structural equation modeling (SEM). SEM is a data analytic method that allows for the quantification and statistical testing of theoretical constructs (Byrne, 1994). This analysis combines both path analysis (PA) and factor analysis (FA) (Boduszek et. al., 2013). PA is a technique that allows for the pictorial demonstration of associations among observed variables in a path diagram (Bollen, 1989). This is typically presented in a multiple regression analysis (Cohen and Cohen, 1983). PA allows for the direct, indirect, and total effect of an observed variable on another to be obtained (Bollen, 1989; Byrne, 1994). In this project, the structural level of analysis determines the relationship between latent variables. Five latent variables were identified in the current project: criminal association, cognitive centrality, in-group affect, in-group ties, and criminal attitudes. 


\section{Results}

Descriptive Statistics and Correlations

Descriptive statistics including mean $(M)$, standard deviation $(S D)$, and range for

all variables are presented in Table 2, along with Cronbach's alpha reliability

(Cronbach, 1951). Correlations between all continuous variables were investigated using

Pearson product-moment correlation coefficient and are presented in Table 3.

Table 1: Descriptive Statistics

\begin{tabular}{lcc}
\hline & Frequency & Percentage \\
\cline { 2 - 3 } Gender & 99 & 49.5 \\
Female & 94 & 47 \\
Male & 7 & 3.5 \\
Non-Binary/Other & & \\
Age & 30.77 & 8.03492 \\
Average Age of Participant & & \\
Race & 120 & 60 \\
White & 35 & 17.5 \\
Black/African American & 18 & 9 \\
Hispanic/Latinx & 10 & 5 \\
Asian & 4 & 2 \\
Alaskan Native/Native American & 4 & 2 \\
Native Hawaiian/Pacific Islander & 9 & 4.5 \\
Other & & \\
Conviction & 89 & 44.5 \\
Burglary/Theft & 25 & 12.5 \\
Drug Offences & 82 & 41 \\
Violent Offences & 4 & 2 \\
Sex Offences & 200 & \\
\hline Participants (n) & & \\
\hline Note: Mean and SD are reported for Age & & \\
\hline
\end{tabular}

Note: Mean and SD are reported for Age 
Table 1: Descriptive Statistics (Cont.)

\begin{tabular}{lcc}
\hline & Frequency & Percentage \\
\cline { 2 - 2 } Locale & 109 & \\
Urban & 86 & \\
Suburban & 5 & 42.5 \\
Rural & & 2.5 \\
Education & 36 & \\
No HS & 15 & \\
Some HS & 33 & 7.5 \\
HS/GED & 28 & 16.5 \\
Some College & 11 & 14 \\
Trade/Vocational/Technical Training & 16 & 5.5 \\
Associate's Degree & 55 & 8 \\
Bachelor's Degree & 6 & 27.5 \\
Graduate Degree & & 3 \\
Relationship Status & 107 & \\
Single & 53 & 53.5 \\
Living w/Partner & 29 & 26.5 \\
Married & 7 & 14.5 \\
Divorced/Separated & 4.5 \\
Widowed & & 2
\end{tabular}

Table 2: Descriptive Statistics of the Measures Included in the Study

\begin{tabular}{lccc}
\hline Scale & $M$ & $S D$ & Range \\
\hline Number of criminal friends & 7.28 & 4.91 & $0-16$ \\
Time with criminal friends & 8.25 & 3 & $1-16$ \\
Peer relations & 20.5 & 5 & $7-35$ \\
Criminal identity & 20.41 & 6.54 & $8-40$ \\
$\quad$ Centrality & 8.7 & 3.37 & $3-15$ \\
$\quad$ In-group affect & 4 & 2.15 & $2-10$ \\
$\quad$ In-group ties & 8.5 & 3.1 & $3-15$ \\
Criminal thinking & 23 & 6.85 & $0-36$ \\
Violence & 7 & 3.05 & $0-12$ \\
Entitlement & 7.5 & 2.55 & $0-12$ \\
Intent & 7.35 & 2.68 & $0-12$ \\
\hline
\end{tabular}




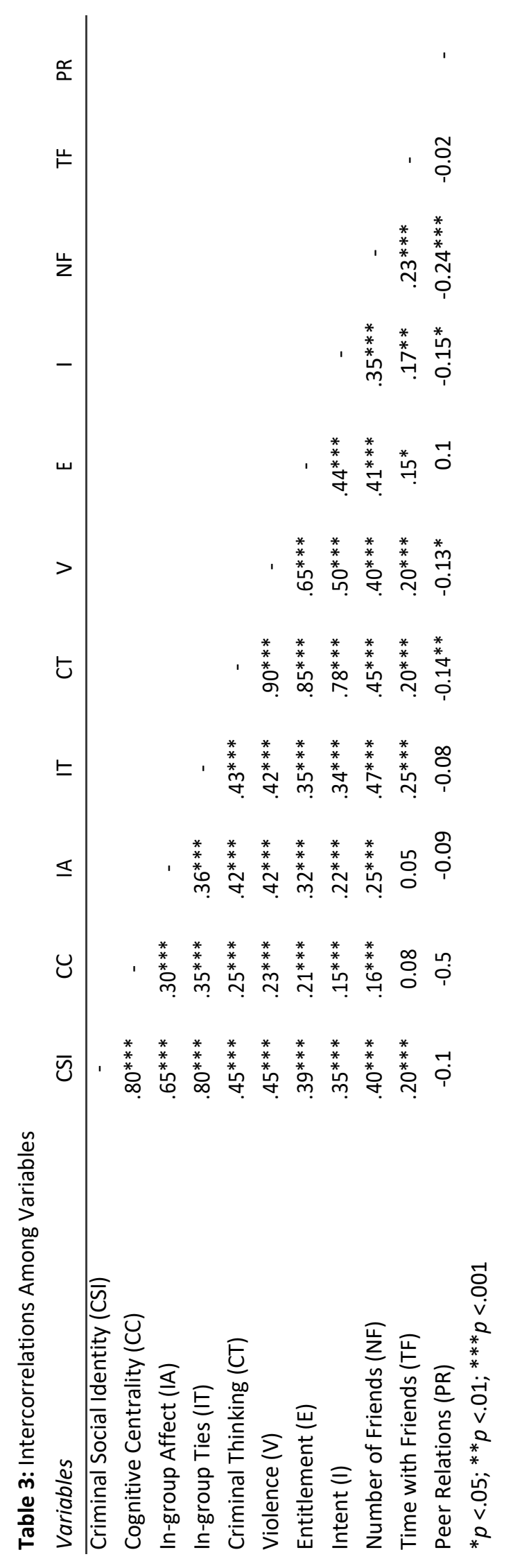




\section{Measurement Level}

In order to appropriately incorporate criminal identity into the structural model of criminal thinking style, three separate CFA models were estimated. The first model included criminal social identity as a one-factor phenomenon composed of each of the eight items within the scale. The second model included two dimensions of criminal social identity: a first dimension that was composed of the three items measuring cognition (1,2, and 3), as well as a second dimension that was composed of five items measuring relationships with criminal peers $(4,5,6,7$, and 8). The final model of criminal social identity included three factors comprised of cognitive centrality $(1,2$, and 3), in-group affect (4 and 5), and in-group ties (6, 7, and 8).

The three models of criminal social identity are presented in Table 4. As indicated, all fit indices demonstrate improvement in the three factorial model of criminal social identity over the one- and two-factor models. Table 5 reports the correlations between latent factors. Standardized and unstandardized factor loadings for the threefactor model of criminal social identity, criminal peers, and criminal thinking are presented in Table 6. Rather than a full CFA model including all respective items, the model was simplified so that criminal thinking style was measured by only three dimensions (attitudes toward violence, entitlement, and criminal intent). This was done in order to make analysis easier, looking at three dimensions rather than forty-seven separate variables. 
Table 4: Fit Indices for CFA Models of Criminal Social Identity

\begin{tabular}{lccc}
\hline Item & One-Factor Model & Two-Factor Model & Three-Factor Model \\
\hline$\chi^{2}$ & 914.67 & 349.15 & 24.29 \\
$d f$ & 21 & 20 & 18 \\
$p$ & 0 & 0 & 0.13 \\
RMSEA & 0.38 & 0.23 & 0.02 \\
$90 \% \mathrm{Cl}$ & .38 .42 & .23 .28 & .01 .08 \\
SRMR & 0.24 & 0.13 & 0.03 \\
AIC & $6,173.48$ & $5,506.25$ & $5,097.89$ \\
CFI & 0.48 & 0.81 & 0.98 \\
TLI & 0.28 & 0.72 & 0.98 \\
\hline
\end{tabular}

Table 5: Correlations between CFA Latent Factors

\begin{tabular}{lccc}
\hline Item & $C$ & $I A$ & $I T$ \\
\hline Centrality (C) & - & & \\
In-Group Affect (IA) & 0.34 & - & \\
In-Group Ties (IT) & 0.35 & 0.42 & - \\
\hline
\end{tabular}

Note: All factor correlations are statistically significant $(p<.001)$. 


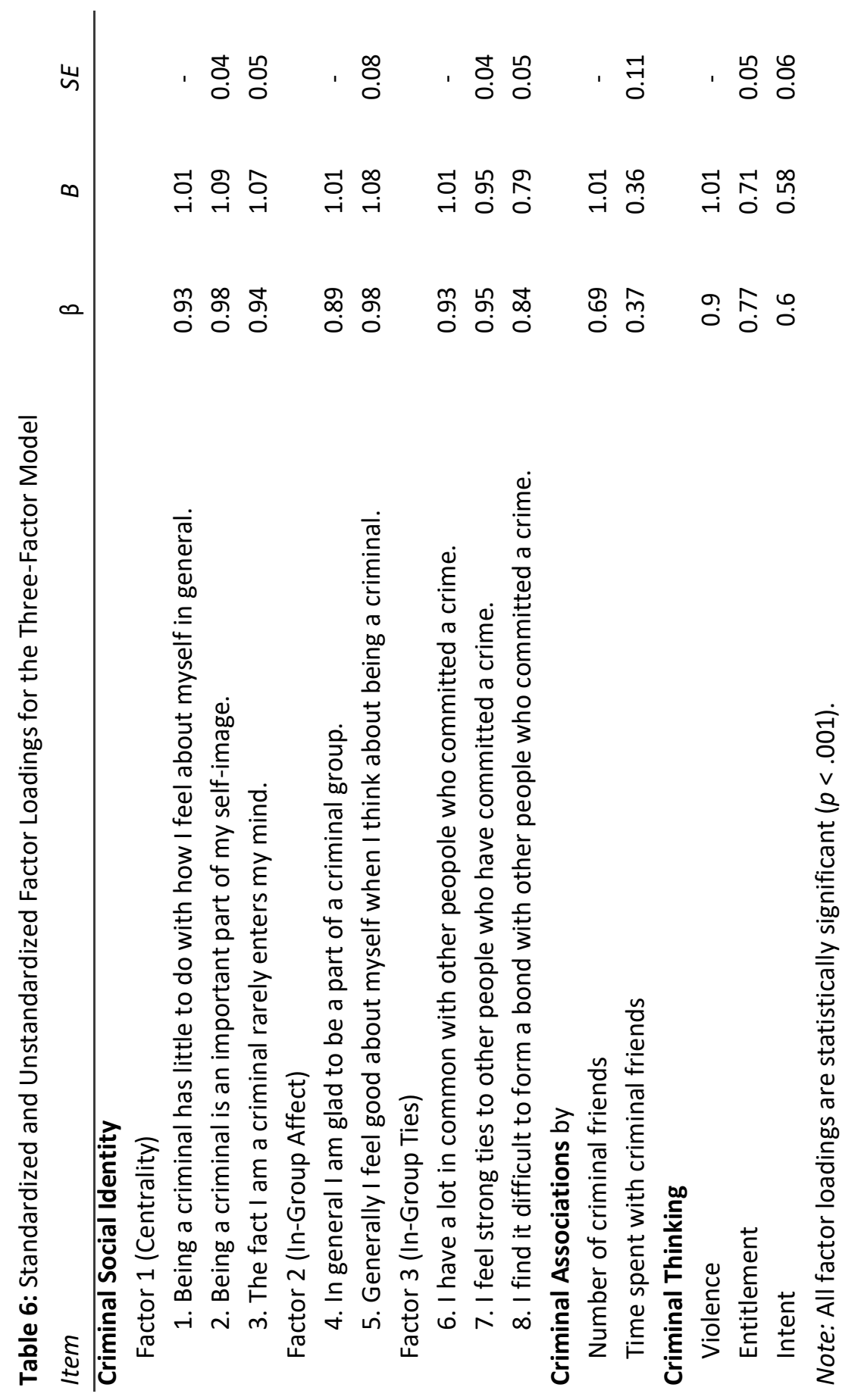




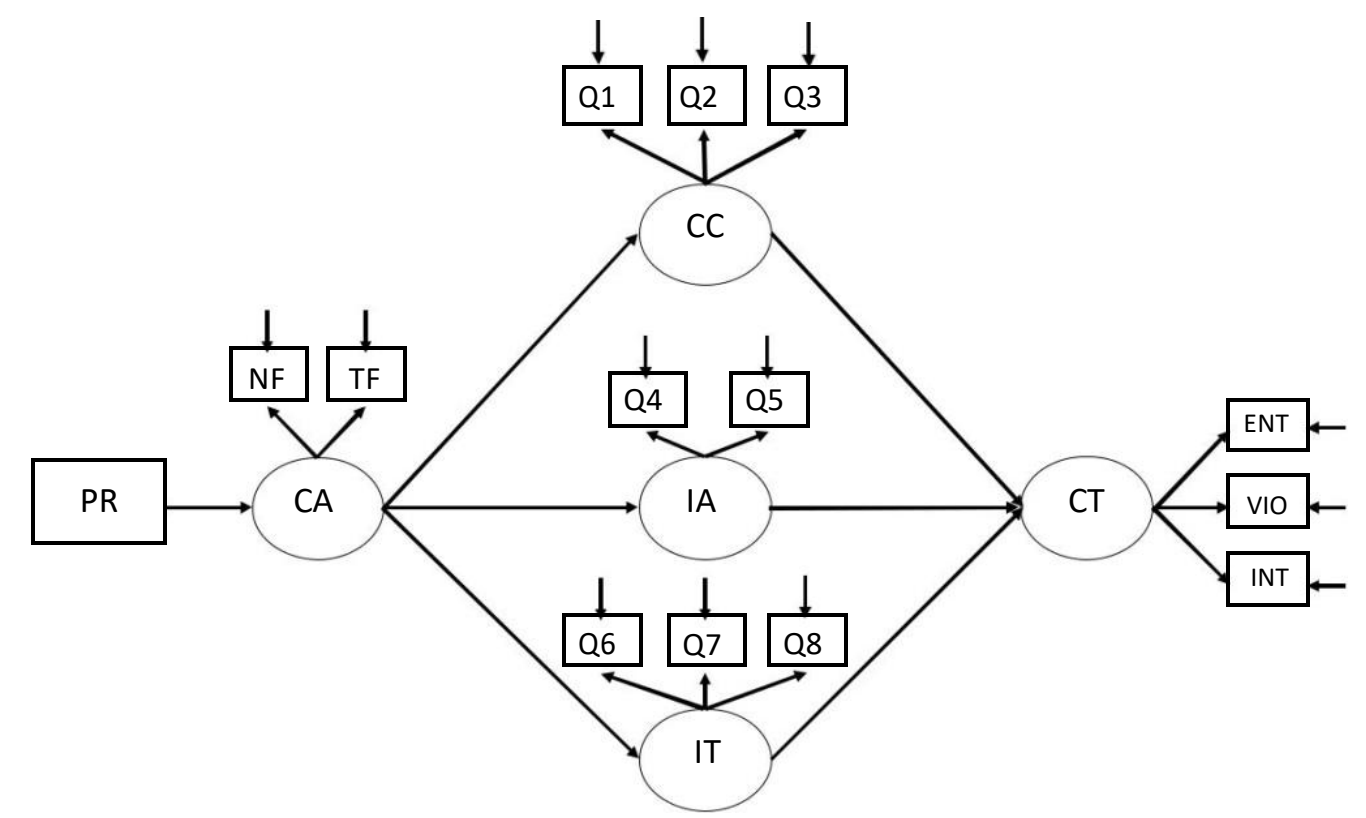

Figure 1: Conceptual SEM of criminal thinking style: $\mathrm{PR}=$ peer relations; $\mathrm{CA}=$ criminal associates; $\mathrm{NF}=$ number of criminal friends; $\mathrm{TF}=$ time with criminal friends; $\mathrm{CC}=$ cognitive centrality; $\mathrm{IA}=$ in-group affect; IT = in-group ties; CT = criminal thinking; Q1-Q8 = MCSI items; ENT; entitlement; $\mathrm{VIO}=$ attitudes towards violence; INT = criminal intent.

CFA indicated that the structural model of criminal thinking can be described through five latent variables: cognitive centrality, in-group ties, in-group affect, criminal associations, and criminal thinking. There was satisfactory fit of the SEM of criminal thinking style mediated by criminal social identity (See Figure 1$)^{5}$. Criminal thinking style mediated by criminal social identity explained $20 \%$ of the variance in cognitive centrality, 32\% of variance in in-group affect, $64 \%$ of variance in in-group ties, $25 \%$ of variance in criminal associates, and $34 \%$ of variance in criminal thinking style.

Table 7 shows the standardized and un-standardized regression weights for the SEM of criminal thinking style. The table demonstrates a direct positive influence of

${ }^{5} \chi^{2}=140.8 ; d f=85, p>.05 ;$ RMSR=.05; RMSEA=.04; CFI=.98; TLI=.97 demonstrate satisfactory fit within the model. A non-significant chi-square has values above .95 for the CFI and TLI and are considered to reflect a good model fit (Hu and Bentler, 1999). RMSR and RMSEA values less than .05 suggest good fit, and values up to .08 indicate reasonable errors of approximation in the population (Browne and Cudeck, 1989). AIC was used to compare alternative models, with the smallest value indicting the best fitting model. 
criminal associates on cognitive centrality $(\beta=.45, p<.001)$, in-group affect $(\beta=.57$, $p<.001)$, and in-group ties $(\beta=.35, p<.001)$. There was also a direct positive impact of both in-group affect $(\beta=.35, p<.001)$ and in-group ties $(\beta=.34, p<.001)$ on criminal thinking. There was no direct relationship observed between cognitive centrality and criminal thinking. An indirect positive relationship was observed between criminal associates and criminal thinking style through both in-group affect $(\beta=.2, p<.001)$ and ingroup ties $(\beta=.27, p<.001)$. This observation at least partially supports the aim of the project as well as the predictions made by Tajfel and Turner's SIT. There was no indication that cognitive centrality acted as a significant mediator in the relationship between criminal peers and criminal thinking. This suggests that sharing knowledge with other group members does not impact criminal thinking styles. 


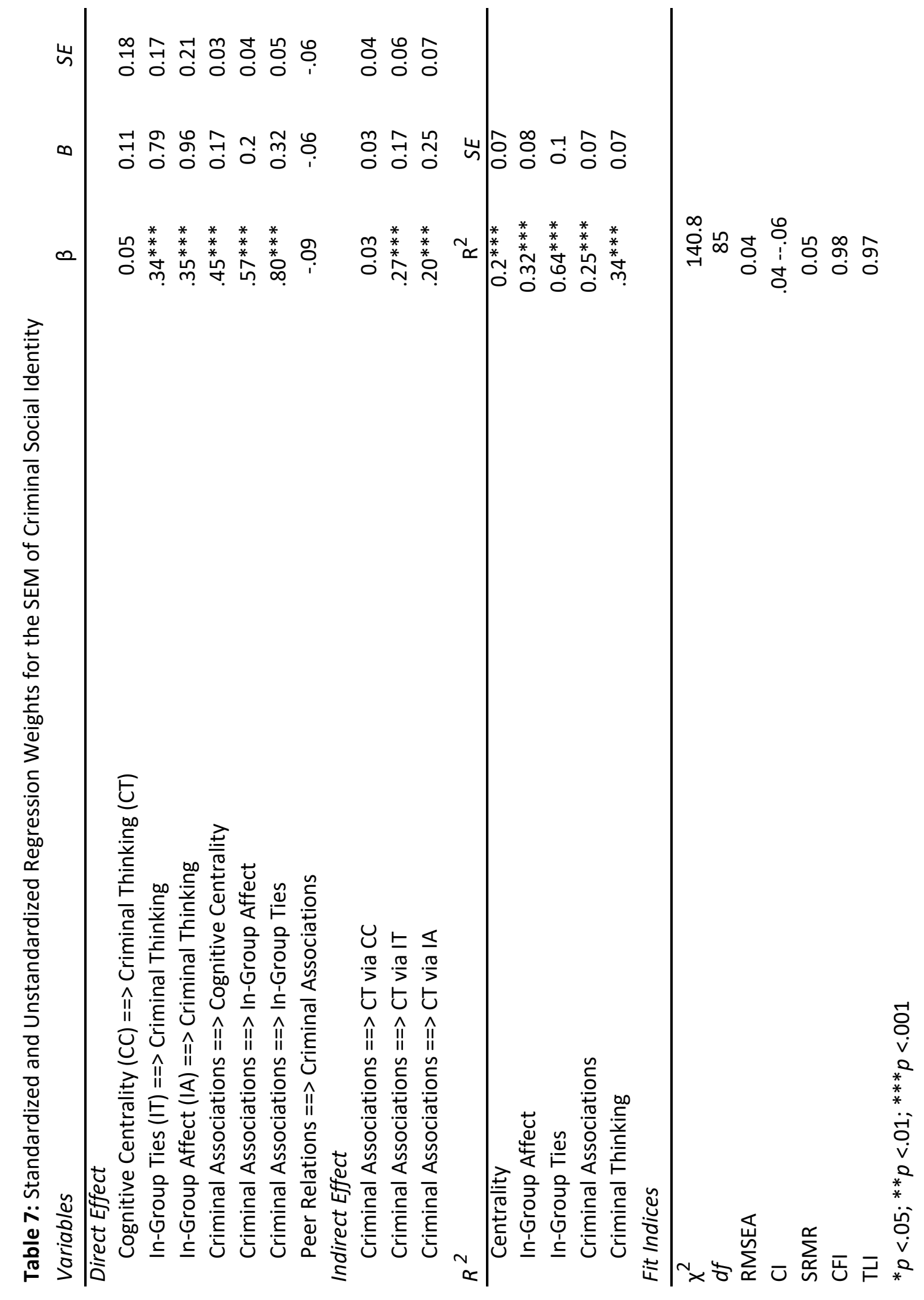




\section{Discussion}

Previous research has almost exclusively focused on examining the relationship between peer associations, particularly those with criminal peers, and the attainment and development of criminal attitudes and behaviors. Prior to this particular project, however, very little research (Boduszek et. al., 2012; Boduszek et. al., 2013; Boduszek, Dhingra, and Debowska, 2016) has sought to test the predictions of SIT (Tajfel and Turner, 1979) as a valid theoretical way of understanding the development of criminal attitudes and behaviors. This project's primary objective was to contribute to this limited body of literature by testing the specific theoretical model brought forth by Boduszek and his colleagues that a criminal social identity is a central mediation factor in the relationship between criminal peers and criminal attitudes and behavior.

The results presented above suggest that the theoretical model of criminal thinking specified in Figure 1 fits the data. In order to investigate said model however, the dimensionality and construct validity of the MCSI warranted testing using CFA techniques. The objective of these pre-analyses was to properly accommodate the variables into an appropriate statistical latent framework. The results suggest that criminal social identity can be conceptualized and measured through three dimensions: cognitive centrality, in-group affect, and in-group ties, supporting $\mathrm{H}_{1}$ of this project.

In regards to direct effects, the analysis suggests that criminal peers play a significant role in the development of a criminal social identity. Analysis also shows the strongest direct effect of criminal peers on in-group ties, suggesting that one's associations with criminal peers play a significant role in understanding what factors contribute to one's development of the emotional connection to, and psychological 
perception of, similarities with other in-group individuals. Associations with criminal peers was also significantly correlated with cognitive centrality, suggesting that individuals develop a strong belief about the importance and value of belonging to a criminal group through their relationships with peers who engage in criminal activity. For these individuals, being a member of a criminal group becomes a central aspect of their life and criminal self-concept. Relations with criminal peers was also significantly correlated with in-group affect, which is consistent with SIT (Tajfel and Turner, 1979). This suggests that the more an individual interacts with criminal peers, the greater the likelihood there is of those individuals developing positive emotional feelings toward belonging to their criminal group.

Data suggest that both in-group affect and in-group ties are significantly linked to the level of criminal attitudes. However, the main objective of this project was to investigate the mediating role of criminal social identity in the relationship between criminal peers and criminal thinking style. The findings suggest that both in-group ties and in-group affect significantly mediate this relationship, supporting the theoretical predictions of SIT (Tajfel and Turner, 1979) as well as $\mathrm{H}_{2}$ of this project. Thus, this project posits that in order for someone to develop a criminal thinking style, two psychosocial components are important: associations with criminal peers and the development of an identity that is consistent with those peers. Previous research suggested there to be a direct, causal relationship between criminal peers and criminal thinking style; however, SIT and related research (Haslam et. al., 1995; Hogg et. al., 1990; Abrams et. al., 1990) indicate the importance of an individual's identification with a particular group, and it is through this process of identification that members of this group adjust their thinking 
style to be more in line with the group's norms and beliefs. Therefore, the results of the analysis suggest that interactions with criminal peers has an influence on the type and intensity of in-group ties and in-group affect, which in turn influences criminal attitudes, supporting the second hypothesis of the project. Essentially, individuals who spend significant amounts of time with criminal others do not have to acquire criminal thinking styles or behaviors. Rather, the results above indicate that the most important factor that gives rise to an individual's attitudes towards crime is the emotional aspect of identification with criminal peers. Thus, in conjunction with SIT, identification with criminal peers is the key factor in the development of criminal thinking.

Additionally, the results support Hogg and Smith's research on group categorization (2007). Categorization of self, according to Hogg and Smith, changes the self-concept of criminals in order to match the identification specified by the criminal category and converts their thinking style and subsequent antisocial behavior to the category prototype. Thus, identity acquired as a result of interactions with criminal peers depersonalizes the thinking style so that it matches the criminal in-group prototype. As Hogg (2001) suggests, this process of depersonalization of self-perception also changes self-conception and incorporates thinking style, feelings, and conduct to the criminal ingroup model. Adding this to previous findings (Haslam et. al., 1995; Hogg et. al., 1990; Abrams et. al., 1990), once the criminal identity is established, the presence of criminal in-group interaction may be unnecessary in maintaining criminal thinking and perceived in-group norms. This provides additional support for the role of identity in the development of criminal thinking and behaviors.

Significance of Study and Limitations 
The concept of a criminal social identity is relatively new, with the earliest mention of it in academia occurring around 1980, and did not gain traction until much more recently, with the work of Asencio and Burke (2011). That research focused solely on incarcerated drug users taking part in a "court-ordered, six-month correctional substance abuse treatment program" in a Southern California medium security correctional facility (Asencio and Burke, 2011:170). While these participants provided a great deal of information on the identity process, the results from this very specific sample are in no way generalizable to any other community. Just as well, the limited amount of research that has been conducted has focused on male inmates in Pakistan, Poland, and Asia (Sherretts and Willmott, 2016). This small amount of literature on the criminal social identity necessitates further investigation.

There are several limitations to this study that warrant acknowledgement. The generalizability of the data is questionable, given that the sample comprised a selfselected group of probationers and parolees from a reentry transition program in Multnomah County, Oregon. While generalizability was not the particular aim of this study, the unavailability of demographic information for both the reentry programs and Multnomah County's Department of Community Justice should be noted, as there is not a population to compare the study's sample. This being said, this replicates previous research which has focused exclusively on incarcerated individuals in medium- to highsecurity prisons, demonstrating the strength of the concepts on different categories of offenders and phases of adjudication.

While the posted flyers stated that participation in or otherwise refusal to participate in the survey would not affect an individual's probation/parole, further 
discussion of this is necessary for a deeper understanding of the ample and the results pertaining to them. The survey did not record whether the participant had decided due to the flyer or referral by the program head or their probation officer to participate in the study. There is of course a potential for there to be a mediation of the probation officer or program head on the sample selection, creating an unintended sample bias. There also may be something to be said about the fact that these participants are already voluntarily participating in a program whose focus is to assist in the successful reentry of adjudicated individuals. All programs included putting their participants in contact with education, housing, and employment resources in an attempt to ease the transition back into pro-social life. One may suggest that this fact may greatly alter the results of the current study, however, I would argue that this point only serves to reinforce the data presented, as this further supports both the previous literature suggesting that through one's interactions with both in-group peers and out-group "others" (i.e. wardens, prison guards, and probation officers), one develops the strong belief regarding the importance and value of belonging to a criminal group (Holsinger, 1999; Backstrom and Bjorklund, 2008; Andrews and Kandel, 1979; and Mills et. al., 2002; 2004) as well as the development of an emotional aspect of identification with criminal peers. With all of this in mind, one cannot ignore the possible selection bias and coercion or steering by parole officers and program heads of the ultimate sample. This study is also unable to understand the reasoning each head of a particular program had for referring particular participants to the study or what was taken into account when selecting individuals for the study. 
Tied to this discussion of identity is one's pro-social employment ties acting as possible mediating or moderating factors. The simple fact that these participants have voluntarily chosen to participate in such a program may suggest a shift in their social identity from one of an anti-social identity to a more pro-social one. This study however is not necessarily equipped to address this possibility, and further study may benefit from addressing this.

This study also does not necessarily facilitate comparison between adjudicated groups such as between incarcerated male and female populations as well as between incarcerated individuals and individuals serving probation/parole. Adding comparison groups in future research may allow for assessment of incarceration and reentry programs and their effectiveness by further understanding how the individuals within these programs are identifying throughout the process of adjudication. 


\section{Conclusion}

This project attempted contribute to an emerging body of literature suggesting that group identity plays a mediating role in the process of the development of particular attitudes. The model of criminal thinking specified in this project contributes to our understanding of the complex interactions between criminal peers and criminal thinking and fills a gap in the criminal and social psychological literature about the role of identity. It can be suggested that the presence of criminal peers may not be sufficient in order to acquire the way of thinking presented by criminal groups without the establishment of strong identifications with that particular group. As such, the findings discussed above propose that in the process of the development of criminal thinking styles that are characteristic of a criminal group, the mediating role of criminal identity as a function of group membership plays a significant role.

Previous literature focuses primarily on the learning of juvenile delinquent behavior, but can be expanded to explain the learning of most behaviors (including criminality and even pro-social behaviors) through interactions with any in-group others. Similarly to this expansion, results of this study may be able to be applied to other groups where behaviors and attitudes are learned through interactions with, and the development of an emotional aspect of identification with, other in-group peers. Take for example an individual who transitions to become a Mahayana Buddhist. As this individual interacts with other Mahayana Buddhists, they will likely develop a strong emotional connection with those ingroup members, and being a part of said group will become a central aspect of their social identity. This suggestion shows that the integration of SIT and its 
theoretical predictions into the sociological literature can be applied to social identity as a whole and is not simply relegated to criminology and criminal groups.

This integration of SIT into the current body of literature has the potential to change the way we think about criminal behavior more broadly as sociologists. While the suggestions of differential association and learning theories were in part correct in that behavior is learned through one's interactions with peers, that learning process is deeper and more nuanced than originally thought. Knowing that an individual's social identity also plays a key role in the development of attitudes and behaviors, sociologists, criminologists, and psychologists alike can begin looking into this social identity process and how it can be used to shift attitudes and behaviors from anti- to pro-social. 


\section{References}

Abele, Susanne, Sandra I. Vaughan-Parsons, and Garold Stasser. 2008. "Information Flow and Influence during Collective Search, Discussion, and Choice." Sonder Forschungs Bereich 504 Working Paper Series.

Abrams, D., M. Wetherell, S. Cochrane, M.A. Hogg, and J.C. Turner. 1990. "Knowing What to Think by Knowing Who You Are: Self-Categorization and the Nature of Norm Formation, Conformity, and Group Polarization.” British Journal of Social Psychology. 29(2)97-119.

Akaike, H. 1974. "A New Look at the Statistical Model Identification." IEEE Transactions on Automatic Control. 19(6):716-23.

Akers, Ronald. 1985. Deviant Behavior: A Social Learning Approach. Belmont, CA: Wadsworth.

Andrews, Kenneth H. and Denise B. Kandel. 1979. Attitude and Behavior: A Specification of the Contingent Consistency Hypothesis." American Sociological Review. 44(2):298-310.

Andrews, D.A. and James Bonta. 1998. The Psychology of Criminal Conduct. New Providence, NJ: Matthew Bender \& Company, Inc.

Asencio, Emily, and Peter Burke. 2011. "Does Incarceration Change the Criminal Identity? A Synthesis of Labeling and Identity Theory Perspectives on Identity Change." Sociological Perspectives. 54205(27):163-182.

Backstrom, Marin and Fredrik Bjorklund. 2008. "Individual Differences in Processing Styles: Validity of the Rational-Experiential Inventory." Scandinavian Journal of Psychology. 49(3)439-446.

Bagozzi, Richard P. and Robert E. Burnkrant. 1979. "Attitude Organization and the Attitude-Behavior Relationship." Journal of Personality and Social Psychology. 37(6):913-29.

Bentler, P.M. 1990. "Comparative Fit Indices in Structural Models." Psychological Bulletin. 107:238-246.

Boduszek, Daniel and Phillip Hyland. 2011. "The Theoretical Model of Criminal Social Identity: Psycho-Social Perspective." International Journal of Criminology and Social Theory. 4(1):604-614.

Boduszek, Daniel, Gary Adamson, Mark Shevlin, and Philip Hyland. 2012. "Development and Validation of a Measure of Criminal Social Identity within a Sample of Polish Recidivistic Prisoners." Criminal Behavior and Mental Health. 22(5):315-24.

Boduszek, Daniel, Gary Adamson, Mark Shevlin, Philip Hyland, and Ashling Bourke. 2013. "The Role of Criminal Social Identity in the Relationship between Criminal Friends and Criminal Thinking Style within a Sample of Recidivistic Prisoners." Journal of Human Behavior in the Social Environment. 23(1):14-28.

Bollen, Kenneth A. 1989. Structural Equations with Latent Variables. Chapel Hill, NC: John Wiley \& Sons, Inc.

Browne, M.W. and R. Cudeck. 1989. "Single Sample Cross-Validation Indices for Covariance Structures.” Multivariate Behavioral Research. 24:445-455.

Burgess, Robert L., and Robert L. Akers. 1966. "A Differential AssociationReinforcement Theory of Criminal Behavior." Social Problems. 14(2):128-47. Byrne, Barbara M. Structural Equation Modeling with EQS and EQS/Windows: Basic 
Concepts, Applications, and Programming. 1994. Thousand Oaks, CA: Sage Publications.

Capara, G.V., V. Cinanni and E. Mazzotti. 1989. "Measuring Attitudes Toward Violence." Personality and Individual Differences. 10(4):479-81.

Cohen, J. and P. Cohen. 1983. Applied Multiple Regression/Correlation Analysis for the Behavioral Sciences. Hillsdale, NJ: Erlbaum.

Cronback, L.J. 1951. "Coefficient Alpha and the Internal Structure of Tests." Psychometrika. 16(3):297-334.

Haslam, S.A., P.J. Oakes, C. McGarty, J.C. Turner, and S. Ontorato. 1995. "Contextual Changes in the Prototypicality of Extreme and Moderate Out-Group Members." European Journal of Social Psychology. 25(1):509-30.

Hogg, Michael A., J.C. Turner, and B. Davidson. 1990. "Polarized Norms and Social Frames of Reference: A Test of the Self-Categorization Theory of Group Polarization." Basic and Applied Social Psychology. 11(1)77-110.

Hogg, Michael A. and D.J. Terry. 2000. "Social Identity and Self-Categorization Processes in Organizational Contexts." Academy of Management Review. 25:12140.

Hogg, Michael A. 2001. “A Social Identity Theory of Leadership." Personality and Social Psychology Review. 5(3):184-200.

Hogg, Michael A. and Joanne R. Smith. 2007. "Attitudes in Social Context: A Social Identity Perspective." European Review of Social Psychology. 18(1)89-131.

Holsinger, H.M. 2000. "Assessing Criminal Thinking: Attitudes and Orientations Influence Behavior." Corrections Today. 61(1):22-5.

Hu, L. and P.M. Bentler. 1999. "Cutoff criteria for fit indexes in covariance structure analysis: Conventional Criteria Versus New Alternatives." Structural Equation Modeling. 6:1-5.

Kameda, T., Y. Ohtsubo, and M. Takezawa. 1997. "Centrality in Sociocognitive Networks and Social Influence: An Illustration in a Group Decision-Making Context." Journal of Personality and Social Psychology. 73:296-309.

Kline, P. 1994. An Easy Guide to Factor Analysis. New York, NY: Routledge.

Losel, Friedrich. 2003. "The Development of Delinquent Behavior" in Handbook of Psychology in Legal Context. Chichester, UK: John Wiley and Sons, Ltd.

Maruna, Shadd and Heith Copes. 2005. "What Have We Learned from Five Decades of Neutralization Research?" Crime and Justice. 32:221-320.

McCallum, R.C., and J.T. Austin. 2000. "Applications of Structural Equation Modeling in Psychological Research." Annual Review of Psychology. 51:201-26.

Mikami, Amori Yee, Margaret A. Boucher, and Keith Humphreys. 2005. "Prevention of Peer Rejection Through a Classroom-Level Intervention in Middle School." Journal of Primary Prevention. 26(1):5-23.

Mills, Jeremy F, Daryl G. Kroner and J.R. Weekes. 1998. "Anger and Institutional Misconduct in a Sample of Violent Offenders." The Prison Journal. 78:45-54.

Mills, Jeremy F. and Daryl G. Kroner. 1999. Measures of Criminal Attitudes and Associates. Unpublished User Guide. Selby, ON.

Mills, Jeremy F., Daryl G. Kroner, and Adelle E. Forth. 2002. "Measures of Criminal Attitudes and Associates (MCAA): Development, Factor Structure, Reliability, and Validity." Assessment. 9(3):240-53. 
Mills, Jeremy F., Dana Anderson, and Daryl G. Kroner. 2004. "The Antisocial Attitudes and Associates of Sex Offenders." Criminal Behavior and Mental Health. 14(2):134-45.

Nesdale, Dre, Anne Maass, Jeff Kiesner, Kevin Durkin, Judith Griffiths, and Bre James. 2009. "Effects of Peer Group Rejection and a New Group's Norms on Children't Intergroup Attitudes.” British Journal of Developmental Psychology. 27(4):799814.

Newberry, Michelle, and John Birtchnell. 2011. "Negative Relating and Offense Type.” Journal of Criminal Psychology. 1(1):24-35.

O’Connor, Tom. 2005. "Learning Theories of Crime." North Carolina Wesleyan College. Retrieved April 20,2017. (http://faculty.ncwc.edu/TOConnor/301/301lect10.htm).

O'Grady, William. 2011. Crime in Canadian Context: Debates and Controversies. Oxford, England: Oxford University Press.

Pfohl, Stephen. 1994. Images of Deviance and Social Control. New York, NY: McGrawHill.

Rhodes, L.M. 1979. "Impact of Social Anchorage on Prisonization." Dissertation Abstracts International. 40, 1694A. (UMI No. 79-19, 101).

Scarpitti, Frank R., Amie L. Nielsen, and J. Mitchell Miller. 2009. Crime and Criminals: Contemporary and Classic Readings in Criminology. New York, NY: Oxford University Press.

Sherretts, Nicole and Dominic Willmott. 2016. "Construct Validity and Dimensionality of the Measure of Criminal Social Identity Using Data drawn from American, Pakistani, and Polish Inmates." Journal of Criminal Psychology. 6(3):134-43.

Simourd, David J. and Jennifer VanDeVen. 1999. “Assessment of Criminal Attitudes: Criterion-Related Validity of the Criminal Sentiments Scale-Modified and Pride in Delinquency Scale." Criminal Justice and Behavior. 26(1):90-106.

Steiger, J.H. 1990. "Structural Medel Evaluation and Modification: An Interval Estimation Approach.” Multivariate Behavioral Research. 25:173-180.

Stevenson, Sally, Guy Hall, and Michael Innes. 2003. "Sociomoral Reasoning and Criminal Sentiments in Australian Men and Women Violent Offender and NonOffenders." International Journal of Forensic Psychology. 1:111-19.

Sutherland, Edwin Hardin and Donal Ray Cressey. 1978. Criminology. Philadelphia, PA: Lippincott.

Sutherland, Edwin Hardin, Donald Ray Cressey, and David F. Luckenbill. 1992. Principles of Criminology. Dix Hills, NY: General Hall.

Sweet, Stephen A. and Karen Grace-Martin. 2011. Data Analysis with SPSS: A First Course in Applied Statistics. England, London: Pearson.

Sykes, Gresham and David Matza. 1957. "Techniques of Neutralization: A Theory of Delinquency." American Sociological Review. 22(6):664-70.

Tajfel, Henri and John Turner. 1979. "An Integrative Theory of Intergroup Conflict." Pp. 33-47 in The Social Psychology of Intergroup Relations. Monterey, CA:

Brooks/Cole.

Tucker, L.R. and C. Lewis. 1973. "The Reliability Coefficient for Maximum Likelihood Factor Analysis.” Psychometrika. 38:1-10.

Turner, J.C. 1987. "A Self-Categorization Theory.” Pp. 42-67 in Rediscovering the Social Group: A Self-Categorization Theory. Oxford, UK: Blackwell. 
Turner, J.C. and K.J. Reynolds. 2010. "The Story of Social Identity.” Pp.13-32 in Rediscovering Social Identity: Key Readings. New York, NY: Psychological Press.

Viatro, Frank, Mara Brendgen, and Richard E. Tremblay. 2000. Influence of Deviant Friends on Delinquency: Searching for Moderator Variables." Journal of Abnormal Child Psychology. 28(4):313-25.

von Oertzen, T., A.M. Brandmaier, and S. Tsang. In Press. "Structural Equation Modeling with Onyx." Structural Equation Modeling: A Multidisciplinary Journal. doj: 10.1080/10705511.2014.935842.

Walters, Glenn D. and T.W. White. 1989. "The Thinking Criminal: A Cognitive Model of Lifestyle Criminality." Criminal Justice Research Bulletin. 4:1-10.

Walters, Glenn D. 2006. "Appraising, Researching and Conceptualizing Criminal Thinking: A Personal View." Criminal Behavior and Mental Health. 16(2):87-99.

Zimbardo, Philip G. 1970. "The Human Choice: Individuation, Reason, and Order Versus Deindividuation, Impulse, and Chaos.” Pp. 237-307 in Nebraska Symposium on Motivation, 1969. Lincoln, NE: University of Nebraska Press. 
Appendix A: Recruitment Flyer

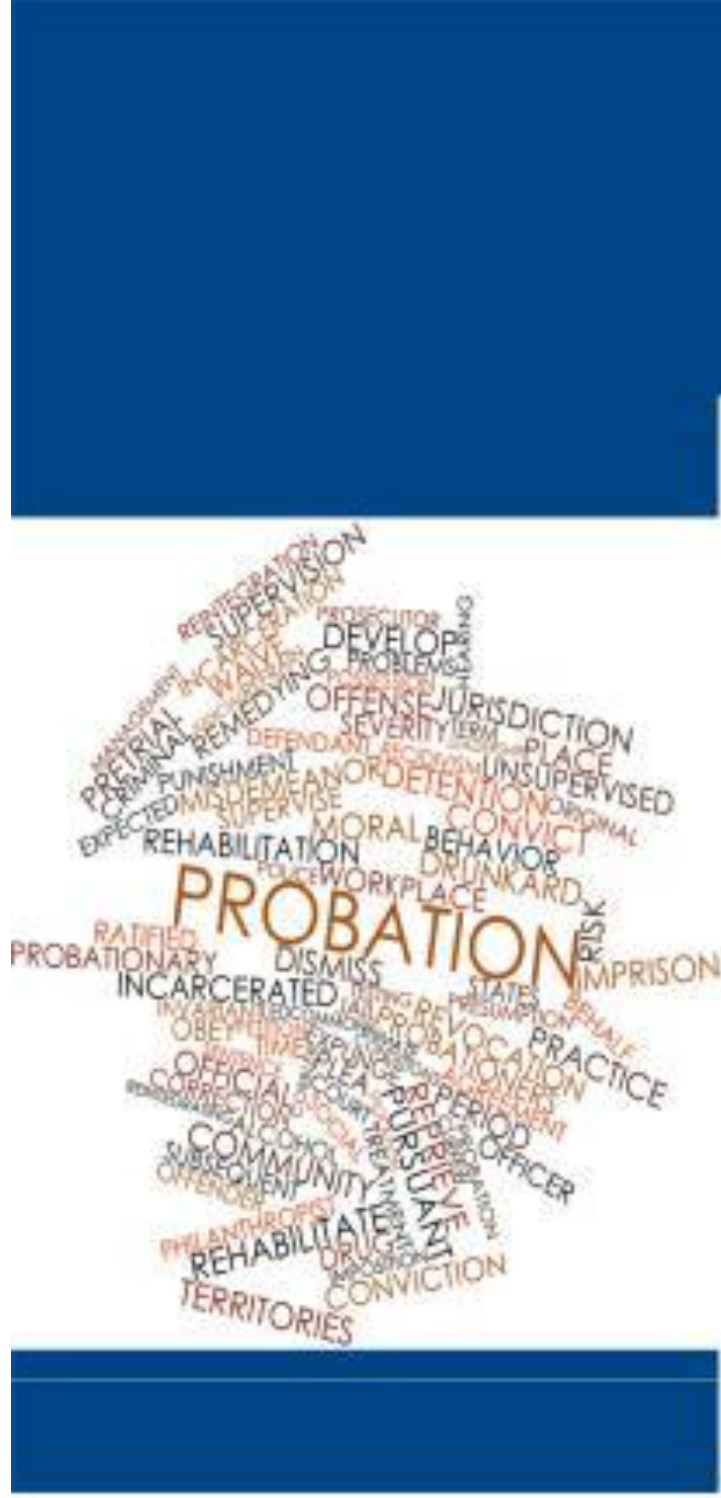

Interested? Please contact Quinton Alexander at (503)725-3967 or quin4@pdx.edu Questions can be directed to the contact information above.

\section{A Research Study: \\ The Social Identity of Probationers and Parolees}

Researchers at Portland State University want to investigate the formation of a social identity among probationers and parolees in Multnomah County. In a private, one-on-one setting, investigators want to survey you on the factors related to your social identity formation.

In order to participate you must:

- Currently be on probation, parole, bench probation, postprison supervision, or close street supervision in Multnomah County

- Be 18 years of age or older

What you can expect:

- A researcher will set up a day and time that is convenient for you to meet.

- All participant information will be kept anonymous and confidential.

-Participation in this study or refusal to participate will not positively or negatively affect your probation/parole.* 
Appendix B: Survey

\section{Demographic Questions}

1. How would you describe your gender:

2. What is your age:

3. What race or ethnicity would you use to describe yourself (circle all that apply):

Black or African American Hispanic or Latino Asian White

Alaskan Native or American Indian Native Hawailan or Pacific Islander

Other:

4. What crime were you most recently convicted of:

5. Where do you live (please circle one): Urban Ruburban

6. What is the highest level of education you have received (please circle one):

No High School Some High School High School/GED

Some College Trade/Vocational/Technical Training

Associate'sDegree Bachelor'sDegree Graduate Degree

7. What is your relationship status (please circle one):

Single Living with Partner Married

Divorced/Separated Widowed 


\section{Survey Questions}

1. Being a criminal has little to do with how I feel about myself in general

$$
\text { Strongly Disagree Disagree Sometimes Agree Strongly Agree }
$$

2. Being a criminal is an important part of my self-image

$$
\text { Strongly Disagree Disagree Sometimes Agree Strongly Agree }
$$

3. The fact I am a criminal rarely enters my mind

$$
\text { Strongly Disagree Disagree Sometimes Agree Strongly Agree }
$$

4. In general I am glad to be a part of a criminal group

Strongly Disagree Disagree Sometimes Agree Strongly Agree

5. Generally I feel good about myself when I think about being a criminal

Strongly Disagree Disagree Sometimes Agree Strongly Agree

6. I have a lot in common with other people who have committed a crime

Strongly Disagree Disagree Sometimes Agree Strongly Agree

7. I feel strong ties to other people who have committed a crime

Strongly Disagree Disagree Sometimes Agree Strongly Agree

8. I find it difficult to form a bond with other people who have committed a crime

Strongly Disagree Disagree Sometimes Agree Strongly Agree

Consider the 4 adults you spend the most time with in the community. No names please of the people you are referring to. Then answer the questions to the best of your knowledge.

1.

A. How much of your free time do you spend with person \#1?

$$
\text { less than } 25 \% \quad 25 \%-50 \% \quad 50 \%-75 \% \quad 75 \%-100 \%
$$

B. Has person \#1 ever committed a crime?

C. Does person \#1 have a criminal record? Yes No

D. Has person \#1 ever been to jail? Yes No

E. Has person \#1 tried to involve you in a crime? Yes No 
2.

A. How much of your free time do you spend with person \#2?

$$
\text { less than } 25 \% \quad 25 \%-50 \% \quad 50 \%-75 \% \quad 75 \%-100 \%
$$

B. Has person \#2 ever committed a crime? $\quad$ Yes No

C. Does person \#2 have a criminal record? ?es No

D. Has person \#2 ever been to jail? Yes No

E. Has person \#2 tried to involve you in a crime? Yes No

3.

A. How much of your free time do you spend with person \#3? less than $25 \% \quad 25 \%-50 \% \quad 50 \%-75 \% \quad 75 \%-100 \%$

B. Has person \#3 ever committed a crime? Yes No

C. Does person \#3 have a criminal record? Yes No

D. Has person \#3 ever been to jail? Yes No

E. Has person \#3 tried to involve you in a crime? Yes No

4.

A. How much of your free time do you spend with person \#4?

$$
\text { less than } 25 \% \quad 25 \%-50 \% \quad 50 \%-75 \% \quad 75 \%-100 \%
$$

B. Has person \#4 ever committed a crime? $\quad$ Yes No

C. Does person \#4 have a criminal record? Yes No

D. Has person \#4 ever been to jail? Yes No

E. Has person \#4 tried to involve you in a crime? Yes No

\section{$A=$ Agree $\quad D=$ Disagree}

A D 1. It is understandable to hit someone who insults you. 
A D 2. Stealing to survive is understandable.

A D 3. I am not likely to commit a crime in the future.

A D 4. I have a lot in common with people who break the law.

A D 5. There is nothing wrong with beating up a child molester.

A D 6. A person is right to take what is owed them, even if they have to steal it.

A D 7. I would keep any amount of money I found.

A D 8. None of my friends have committed crimes.

A D 9. sometimes you have to fight to keep your self-respect.

A D 10. I should be allowed to decide what is right and wrong.

A D 11. I could see myself lying to the police.

A D 12. I know several people who have committed crimes.

A D 13. Someone who makes you very angry deserves to be hit.

A D 14. Only I should decide what I deserve.

A D 15. In certain situations I would try to outrun the police.

A D 16. I would not steal, and I would hold it against anyone who does.

A D 17. People who get beat up usually had it coming.

A D 18. I should be treated like anyone else no matter what I have done.

A D 19. I would be open to cheating certain people.

A D 20. I always feel welcomed around criminal friends.

A D 21. It is alright to fight someone if they stole from you.

A D 22. It is wrong for a lack of money to stop you from getting things.

A D 23. I could easily tell a convincing lie.

A D 24. Most of my friends don'thave criminal records.

A D 25. It is not wrong to hit someone who puts you down.

A D 26. A hungry man has the right to steal. 
A D 27. Rules will not stop me from doing what I want.

A D 28. I have friends who have been to jail.

A D 29. Child molesters get what they have coming.

A D 30. Taking what is owed you is not really stealing.

A D 31. I would not enjoy getting away with something wrong.

A D 32. None of my friends has ever wanted to commit a crime.

A D 33. It is not wrong to fight to save face.

A D 34. Only I can decide what is right and wrong.

A D 35. I would run a scam if I could get away with it.

A D 36. I have committed a crime with friends.

A D 37. Someone who makes you really angry shouldn'tcomplain if they get hit.

A D 38. A person should decide what they deserve out of life.

A D 39. For good reason, I would commit a crime.

A D 40. I have friends who are well known to the police.

A D 41. there is nothing wrong with beating up someone who asks for it.

A D 42. No matter what I have done, it is only right to treat me like everyone else.

A D 43. I will not break the law again.

A D 44. It is reasonable to fight someone who cheated you.

A D 45. A lack of money should not stop you from getting what you want.

A D 46. I would be happy to fool the police.

Mark an $X$ on the line to the left of the answer that is most like how the respondent feels for each question.

1. How many students in your class did you get along with? These can be people who were already your friends, or they can be people you did not know that well but would have liked to know better.

I got along with everybody in my class. 
I got along with most of them.

I got along with half of them.

I got along with few of them.

I got along with nobody in my class.

2. How many students in your class did you not get along with? These were people who you did not like and did not want to be around.

I got along with everybody in my class.

I did not get along with a few of them.

I I did not get along with half of them.

I did not get along with most of them.

I did not get along with anybody in my class.

3. How many students in your class respected you and listened to what you had to say?

Nobody

Only a few of them

Half of them

Most of them

All of them

4. How many students in your class teased you, put you down, or picked on you?

Nobody

Only a few of them

Half of them

Most of them

_ All of them

5. How many students in your class did you like working with on group projects?

I liked to work on projects with everybody in my class.

I liked to work on projects with most of them.

I liked to work on projects with half of them.

I liked to work on projects with a few of them.

_ I liked to work on projects with none of them.

6. Suppose your teacher was picking teams of four students for a group project. How many students in your class would you not want to be on your team?

I would want everybody in my class on my team.

_ I would not want a few of them.

_ I would not want half of them.

_ I would not want most of them.

_ I would not want any of them.

7. In your class, how did you feel about working in groups?

I liked it a lot. 
I liked it a little bit.

Sometimes I liked it and sometimes I did not.

I disliked it a little bit.

I disliked it a lot. 